LAWRENCE LIVERMORE N A T IO N A L LABORATORY

\title{
Carbon Nanotube-Based Permeable Membranes
}

J. K. Holt, H. G. Park, O. Bakajin, A. Noy, T. Huser, D. Eaglesham

April 26, 2004

Materials Research Society Spring Meeting San Francisco, CA, United States April 12, 2004 through April 16, 2004 
This document was prepared as an account of work sponsored by an agency of the United States Government. Neither the United States Government nor the University of California nor any of their employees, makes any warranty, express or implied, or assumes any legal liability or responsibility for the accuracy, completeness, or usefulness of any information, apparatus, product, or process disclosed, or represents that its use would not infringe privately owned rights. Reference herein to any specific commercial product, process, or service by trade name, trademark, manufacturer, or otherwise, does not necessarily constitute or imply its endorsement, recommendation, or favoring by the United States Government or the University of California. The views and opinions of authors expressed herein do not necessarily state or reflect those of the United States Government or the University of California, and shall not be used for advertising or product endorsement purposes. 
MRS Spring 2004 - UCRL-CONF-203753

\title{
Carbon Nanotube-Based Permeable Membranes
}

Jason K. Holt, Hyung Gyu Park, Olgica Bakajin, Aleksandr Noy, Thomas Huser, and David Eaglesham

Chemistry and Materials Science Directorate, Lawrence Livermore National Laboratory

Livermore, CA 94551, USA

\begin{abstract}
A membrane of multiwalled carbon nanotubes embedded in a silicon nitride matrix was fabricated for use in studying fluid mechanics on the nanometer scale. Characterization by fluorescent tracer diffusion and scanning electron microscopy suggests that the membrane is void-free near the silicon substrate on which it rests, implying that the hollow core of the nanotube is the only conduction path for molecular transport. Assuming Knudsen diffusion through this nanotube membrane, a maximum helium transport rate (for a pressure drop of $1 \mathrm{~atm}$ ) of $0.25 \mathrm{cc} / \mathrm{sec}$ is predicted. Helium flow measurements of a nanoporous silicon nitride membrane, fabricated by sacrificial removal of carbon, give a flow rate greater than $1 \times 10^{-6} \mathrm{cc} / \mathrm{sec}$. For viscous, laminar flow conditions, water is estimated to flow across the nanotube membrane (under a $1 \mathrm{~atm}$ pressure drop) at up to $2.8 \times 10^{-5} \mathrm{cc} / \mathrm{sec}(1.7$ $\mu \mathrm{L} / \mathrm{min})$.
\end{abstract}

\section{INTRODUCTION}

Carbon nanotubes, with their unique mechanical, electrical, and chemical properties, have been used for a variety of applications, ranging from reinforced polymer composites [1] to field-emission devices [2] and DNA sensors [3]. Consideration of their hollow cores, ranging from $\sim 1 \mathrm{~nm}$ in the case of single wall nanotubes to $\sim 10 \mathrm{~nm}$ in the case of multiwall nanotubes, suggests they may also find applications in the area of molecular separations. This size scale is comparable to that of typical biological macromolecules, making these materials candidates for biosensing. On this size scale, however, little is known about the behavior of fluids; deviations from continuum transport are to be expected as the channel size becomes comparable to molecular diameters. Furthermore, questions arise as to the wetting properties of polar fluids like water in the hydrophobic channel of a carbon nanotube. In recent years, a number of molecular dynamics simulations have attempted to model this system. Many exotic predictions have been made, from the formation of novel phases of ice [4] and pulsed one-dimensional water transport [5], to the spontaneous insertion of ss-DNA into a single wall carbon nanotube [6]. What has been lacking, however, is a platform for experimentally verifying some of these predictions. To date, there has been just one experimental study [7] claiming to demonstrate gas and ionic transport through a polystyrene/nanotube membrane. Here we aim to reproducibly produce a robust, nanoporous membrane in which the hollow cores of multiwall carbon nanotubes serve as the only conduit for molecular transport. Alternatively, these nanotubes would serve as a template for the production of nanoporous silicon nitride and silicon oxide, materials that would allow for relatively easy surface functionalization to permit chemically specific as well as size-based separations. 


\section{EXPERIMENTAL FABRICATION}

The starting material is single-side polished test grade $\mathrm{Si}(100)$. The catalyst used for nanotube growth is iron, deposited by electron beam evaporation to a thickness between $2.5-5.0 \mathrm{~nm}$. The samples are oxidized shortly after the deposition of iron $\left(500^{\circ} \mathrm{C}, 1\right.$ hour, $\left.10 \mathrm{sccm} \mathrm{O}_{2}\right)$ to stabilize the surface. Samples are next placed into an atmospheric pressure CVD system (1" diameter tube furnace) and initially exposed to a reducing environment of $\mathrm{Ar} / \mathrm{H}_{2}(600 \mathrm{sccm} / 400 \mathrm{sccm})$ as the temperature is ramped up to the growth temperature of $850^{\circ} \mathrm{C}$. At this point, discrete iron nanoparticles of order 20$30 \mathrm{~nm}$ are formed which serve as the catalyst and nucleation sites for nanotube growth. After temperature stabilization, $\mathrm{C}_{2} \mathrm{H}_{4}(1000 \mathrm{sccm})$ is introduced to initiate growth. Nanotube growth occurs

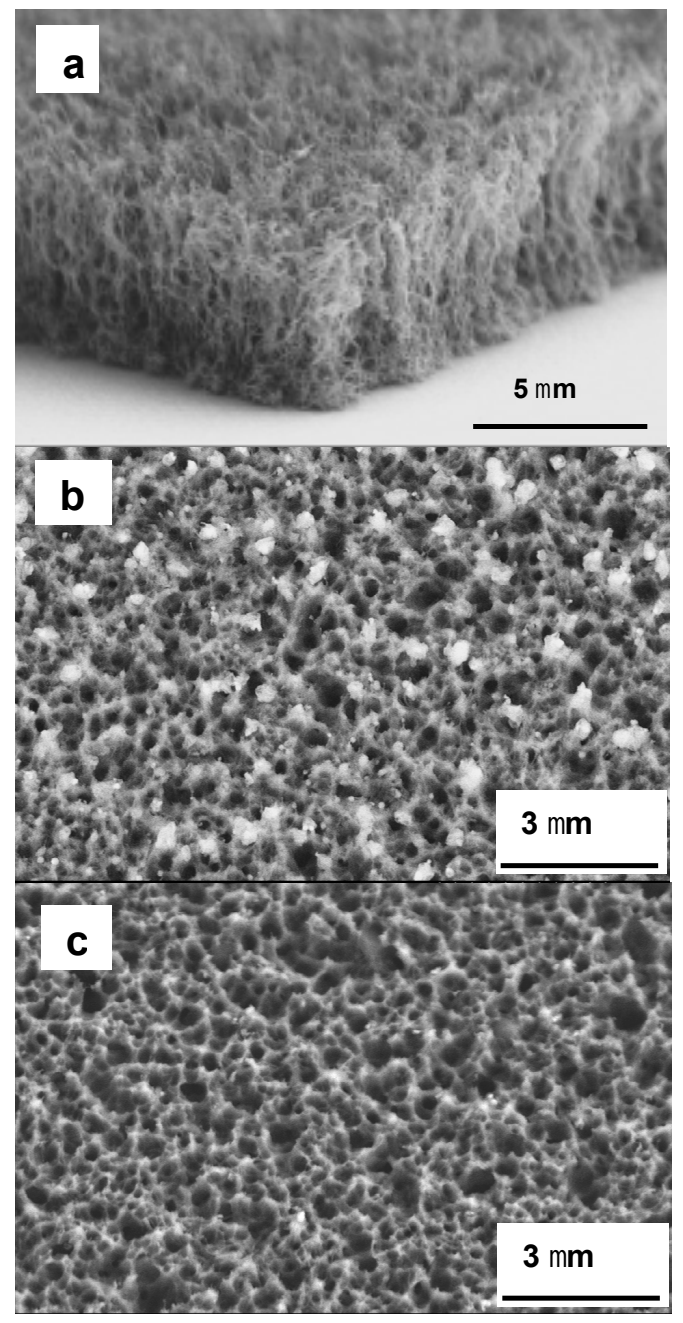

Figure 1. (a) As-grown array of multiwalled carbon nanotubes, (b) backside of membrane after $\mathrm{KOH}$ and reactive ion etching; bright particles were confirmed by EDX to be residual iron catalyst nanoparticles, (c) same sample as (b), but after 24 hour $\mathrm{HCl}$ treatment. 
typically for 20 minutes and results in a dense array ("forest") of multiwalled nanotubes of $\sim 5 \mu \mathrm{m}$ length and 20-50 nm diameter, as shown in Fig. 1a. As-grown carbon nanotubes adhere poorly to the silicon substrate and the spaces between them must be filled by a rigid, impermeable material that conforms to the nanotube, to enable further processing into a membrane. Silicon nitride was found to possess these desirable properties. Thus, after tube growth, the samples are placed into a low pressure CVD furnace to deposit a low-stress silicon nitride layer. A target film thickness of $800 \mathrm{~nm}$ was found sufficient to fill the bulk of the $10 \mu \mathrm{m}$ thick nanotube forest. The film was observed to completely encapsulate the nanotubes.

A number of additional processing steps are required in order to produce continuous nanofluidic channels across this structure. Reactive ion etching (RIE) is used to open a window in the silicon nitride layer to expose the backside of the silicon substrate. This is followed by anisotropic $\mathrm{KOH}$ etching of silicon to expose the nanotube film. Energy Dispersive X-ray (EDX) analysis of this interface revealed that discrete iron nanoparticles remain, thus blocking access to the core of the nanotube. To remove these nanoparticles, samples initially underwent an ion milling process, producing a smooth surface with $20-50 \mathrm{~nm}$ pores (overall pore fraction $\sim 0.02$ ). Given that a sizable fraction of the nanoparticles $(\sim 10 \%)$ remain after this step and the small spot size of the ion mill used, an alternative procedure was used. This consisted of a 5 minute RIE treatment to remove several $\mathrm{nm}$ of silicon nitride and further expose the iron nanoparticles. This process also has the effect of oxidizing the nanoparticles, which can then be dissolved by immersion of the sample in concentrated $\mathrm{HCl}$ for 24 hours. Fig. $1 \mathrm{~b}$ shows the surface after the RIE treatment, which is considerably rougher than the ion milled sample, due to the anisotropic nature of the etch and specificity towards silicon nitride. Considerably larger pores, up to $300 \mathrm{~nm}$ diameter, with a much larger membrane pore fraction (0.69) result from this process. These larger pores are suspected to be voids in the membrane that could not be filled by silicon nitride originally, indicating that this sample was over etched.

Subsequent RIE treatments on similar samples were shorter in duration and produced a much smoother surface, comparable to an ion-milled sample. Fig. 1c depicts the same sample after $\mathrm{HCl}$ treatment, showing that virtually all iron nanoparticles were removed. As a final processing step, excess silicon nitride on the opposite side of the sample is removed by RIE to expose the nanotubes and create a continuous nanofluidic channel. Fig. 2 is an illustration of the completed membrane structure.

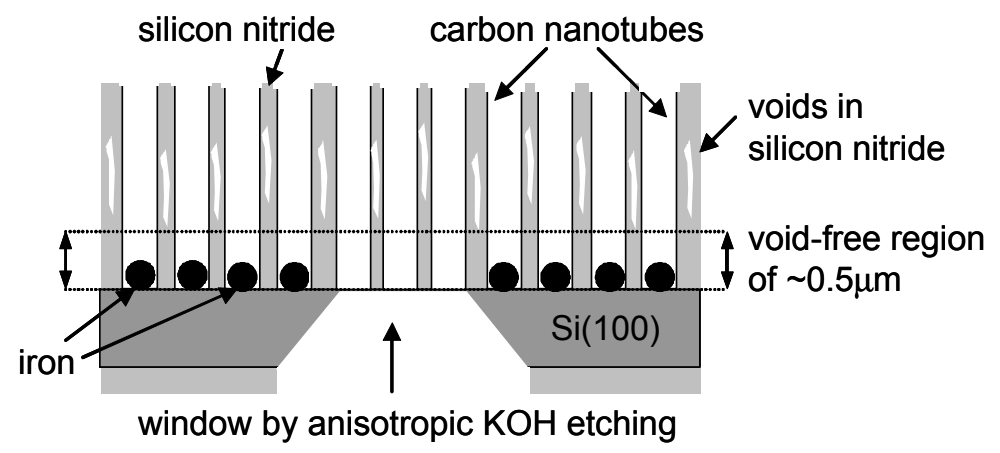

Figure 2. Illustration of the completed carbon nanotube/silicon nitride membrane structure. 


\section{MEMBRANE CHARACTERIZATION}

One of the simplest methods for characterizing the nanotube membranes is through helium leak checking. To make such a measurement, a membrane was mounted in an O-ring sealed flow cell with gas flow connections on either side. On one end, a pressurized helium line was attached, while the other end was open to air. Helium transport through the membrane was measured by use of an external probe from the leak checker, having a flow rate sensitivity of approximately $1 \times 10^{-6} \mathrm{cc} / \mathrm{sec}$ under these conditions. A control experiment utilizing a membrane ( $10 \mu \mathrm{m}$ thickness) that did not undergo RIE to open the nanotube channels was conducted to confirm that there were no cracks in the membrane and that all seals were leak tight, such that a porous membrane would be the only gas transport path. No helium was detected during this experiment and it was also verified that the membrane was sturdy enough to withstand a pressure drop of $1 \mathrm{~atm}$ across. A subsequent experiment utilized a membrane that had undergone the earlier deep RIE and was over etched. To insure that we indeed would have open, nanometer-scale channels suitable for this measurement, the membrane was placed into an oxygen furnace $\left(800^{\circ} \mathrm{C}, 1\right.$ hour, $\left.10 \mathrm{sccm} \mathrm{O}_{2}\right)$ to allow the nanotubes to combust. The resulting nanoporous silicon nitride membrane was then mounted in the flow cell and pressurized with helium on one side. Despite the high porosity, this membrane was also sturdy enough to withstand 1 atm of pressure. The nanoporous nitride was indeed porous throughout and exhibited a leak rate of more than $1 \times 10^{-6} \mathrm{cc} / \mathrm{sec}$, the maximum flow rate measurable on the instrument.

As is clear from the previous results, ensuring that voids are not uncovered due to over etching of the silicon nitride is critical if exclusive nanotube transport is to be demonstrated. Figure 3 is a crosssectional micrograph of the membrane, prior to the nitride etch, revealing a continuous, void-free region of more than $0.5 \mu \mathrm{m}$ from the silicon interface. To demonstrate that voids are not propagating through the membrane, fluorescent tracer experiments were conducted on samples that underwent a short RIE process (sufficient to remove $50 \mathrm{~nm}$ of silicon nitride) on the $\mathrm{KOH}$-side of the sample and a

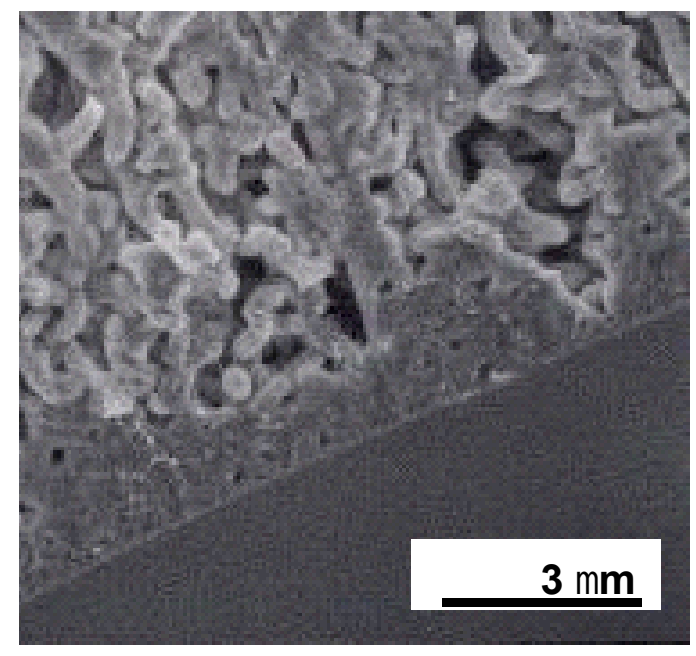

Figure 3. Cross-sectional image of carbon nanotube/silicon nitride membrane. 
longer RIE process (to remove the $800 \mathrm{~nm}$ of excess silicon nitride covering the tips of the nanotubes). Epoxy was used to bond the membrane to reservoirs on either side. In one side, pure water was used, while in the opposite, fluorescently-labeled polystyrene beads of first $100 \mathrm{~nm}$, then $25 \mathrm{~nm}$ diameter were placed in solution. After a period of 48 hours, solution from the pure water reservoir was extracted and examined by fluorescence confocal microscopy. No evidence for diffusion of either labeled polystyrene was present, suggesting that voids, if present, are in the sub- $25 \mathrm{~nm}$ regime. This is in the size range of the multiwall carbon nanotube inner diameter (7-12 nm), suggesting this is the only conduit for molecular transport. Additional experiments are underway to use isotopic tracers of varying polarity (deuterated water, deuterated hexane) to verify that the multiwall nanotubes are indeed open and accessible to molecules. Ion conduction measurements will also be made in parallel with these experiments.

\section{PREDICTED TRANSPORT PROPERTIES}

For the smaller pores of interest in these studies, namely, $10 \mathrm{~nm}$ and below, the behavior of fluids is expected to differ from that of bulk, continuum transport and it is useful to obtain estimates of the expected flow rates. In particular, a comparison of the mean free path at 1 atm for helium $(100 \mathrm{~nm})$ with that of the nanotube inner diameter $(10 \mathrm{~nm})$ suggests that Knudsen diffusion is taking place. With typical tube lengths of $10 \mu \mathrm{m}$, it is clear that the flow is restricted by collisions with the tube walls. These wall collisions can be taken into account by means of the aspect ratio-dependent (length/pore size) Clausing factor [8]. For a representative membrane of $10 \mu \mathrm{m}$ thickness, with $10 \mathrm{~nm}$ pores and a pressure drop of $1 \mathrm{~atm}$, a helium flux of $6.6 \times 10^{8}$ molecules/s per nanotube is obtained. With a measured pore density of $2.9 \times 10^{9} \mathrm{~cm}^{-2}$ from Fig. 1c (compare with a nanotube density of $4.0 \times 10^{10} \mathrm{~cm}^{-}$ ${ }^{2}$ ) and an active membrane area of $0.25 \mathrm{~cm}^{2}$, a He flow rate of $0.018 \mathrm{cc} / \mathrm{sec}$ is calculated. If each nanotube comprised a continuous channel across the membrane, then the flow rate could be as high as $0.25 \mathrm{cc} / \mathrm{sec}$.

Also of interest is an estimate of the flow rate of water across the nanotube membrane. The method of van Rijn et al. [9] was used for this estimate, which assumes viscous, laminar flow and includes correction factors for frictional losses with the walls, interference effects of neighboring pores, and an additional pressure drop near the pore entrance. For a membrane of the same properties as described previously, and a pressure drop of $1 \mathrm{~atm}$, a water flow rate of $2.0 \times 10^{-6} \mathrm{cc} / \mathrm{sec}(0.12 \mu \mathrm{L} / \mathrm{min})$ is estimated. Again, if all nanotubes spanned the membrane, the flow rate could be as high as $2.8 \times 10^{-5}$ $\mathrm{cc} / \sec (1.7 \mu \mathrm{L} / \mathrm{min})$. These values suggest that liquid experiments can be conducted with these membranes and should produce easily measurable and quantifiable results.

\section{CONCLUSION}

A robust platform for the study of nanofluidics has been developed by standard microfabrication techniques. The gas permeability of a nanoporous silicon nitride membrane was verified by helium leak testing and efforts are underway to reduce the size of the pores produced. Estimates of the rate of helium transport through a $10 \mathrm{~nm}$ nanotube membrane are in the range from $0.018-0.25 \mathrm{cc} / \mathrm{sec}$, while water transport through this structure is estimated to be from $0.2-2.8 \times 10^{-5} \mathrm{cc} / \mathrm{sec}(0.12-1.7 \mu \mathrm{L} / \mathrm{min})$. The latter values suggest that liquid-based experiments are indeed possible with both the nanoporous 
nitride and carbon nanotube versions of this membrane. Having the versatility of studying nanometerscale transport in both hydrophilic (silicon nitride) and hydrophobic (carbon nanotube) membranes should bring new insights into the field of nanofluidics.

\section{ACKNOWLEDGEMENT}

This work was performed under the auspices of the US Department of Energy UC/LLNL under Contract \# 7405-Eng-48 with funding from the LDRD program.

\section{REFERENCES}

1. T. V. Sreekumar, T. Liu, B. G. Min, H. Guo, S. Kumar, R. H. Hauge, and R. E. Smalley, Adv. Mat., 16, 58 (2004).

2. Y. Saito, J. Nanosci. Nanotech., 3, 39 (2003).

3. J. Li, H. T. Ng, A. Cassell, W. Fan, H. Chen, Q. Ye, J. Koehne, J. Han, and M. Meyyappan, Nano. Lett., 3, 597 (2003).

4. K. Koga, G. T. Gao, H. Tanaka, and X. C. Zeng, Nature, 412, 802 (2001).

5. G. Hummer, J. C. Rasaiah, and J. P. Noworyta, Nature, 414, 188 (2001).

6. H. Gao, Y. Kong, D. Cui, and C. Ozkan, Nano. Lett., 3, 471 (2003).

7. B. J. Hinds, N. Chopra, T. Rantell, R. Andrews, V. Gavalas, L. G. Bachas, Science, 303, 62 (2004).

8. M. C. Elwenspoek and H. V. Jansen, Silicon Micromachining; Cambridge University Press: Cambridge, England, 1998; pp 216-355.

9. C. J. M. Rijn and M. Elwenspoek, IEEE Conf. MEMS '95, 1995; pp 83-87. 